
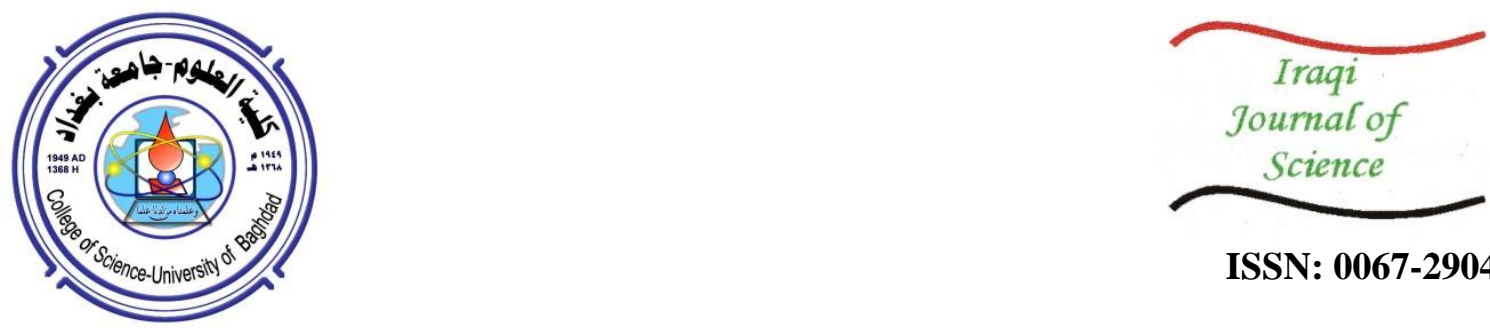

ISSN: 0067-2904

\title{
Petrophysical Analysis of Well Logs for Asmari Reservoir in Abu Ghirab Oil Field, South Eastern Iraq
}

\author{
Buraq Adnan Al-Baldawi \\ Department of Geology, College of Sciences, University of Baghdad, Baghdad, Iraq
}

Received: 31/10/2019

Accepted: 21/1/2020

\begin{abstract}
The present study includes the evaluation of petrophysical properties and lithological examination in two wells of Asmari Formation in Abu Ghirab oil field (AG-32 and AG-36), Missan governorate, southeastern Iraq. The petrophysical assessment was performed utilizing well logs information to characterize Asmari Formation. The well logs available, such as sonic, density, neutron, gamma ray, SP, and resistivity logs, were converted into computerized data using Neuralog programming. Using Interactive petrophysics software, the environmental corrections and reservoir parameters such as porosity, water saturation, hydrocarbon saturation, volume of bulk water, etc. were analyzed and interpreted. Lithological, mineralogical, and matrix recognition studies were performed using porosity combination cross plots. Petrophysical characteristics were determined and plotted as computer processing interpretation (CPI) using Interactive Petrophysics program. Based on petrophysical properties, Asmari Reservoir in Abu Ghirab oil field is classified into three sub formations: Jeribe/ Euphrates and Kirkuk group which is divided into two zones: upper Kirkuk zone, and Middle-Lower Kirkuk zone. Interpretation of well logs of Asmari Formation indicated a commercial Asmari Formation production with medium oil evidence in some ranges of the formation, especially in the upper Kirkuk zone at well X-1. However, well X-2, especially in the lower part of Jeribe/ Euphrates and Middle-Lower Kirkuk zone indicated low to medium oil evidence. Lithology of Asmari Formation demonstrated a range from massive dolomite in Jeribe/ Euphrates zone to limestone in upper Kirkuk zone and limestone and sandstone in middle-lower Kirkuk zone, whereas mineralogy of the reservoir showed calcite and dolomite with few amounts of anhydrite.
\end{abstract}

Keywords: Asmari Formation; Abu Ghirab oil field; petrophysical properties; CPI.

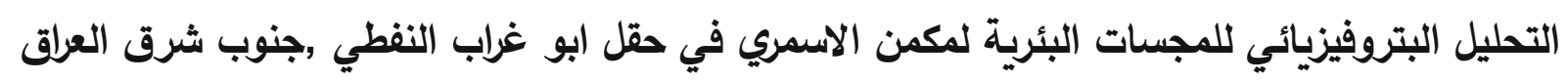

$$
\begin{aligned}
& \text { براق عدنان البلداوي } \\
& \text { قسم علم الارض, كلية العلوم, جامعة بغداد , بغداد , العراق. } \\
& \text { (X-1, تمثل الدراسة الحالية تقييم الصفات البتروفيزيائية والتحليل الصخاري في بئرين لمكمن الاسمري } \\
& \text { and X-2) } \\
& \text { البتروفيزيائي باستخدام معلومات المجسات البئرية لمعرفة الخواص المكمنية لمكمن الاسمري. تم تحويل }
\end{aligned}
$$

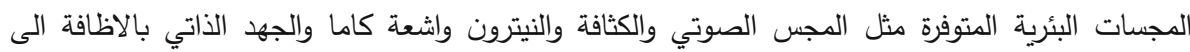

*Email:buraqaddnan@yahoo.com 


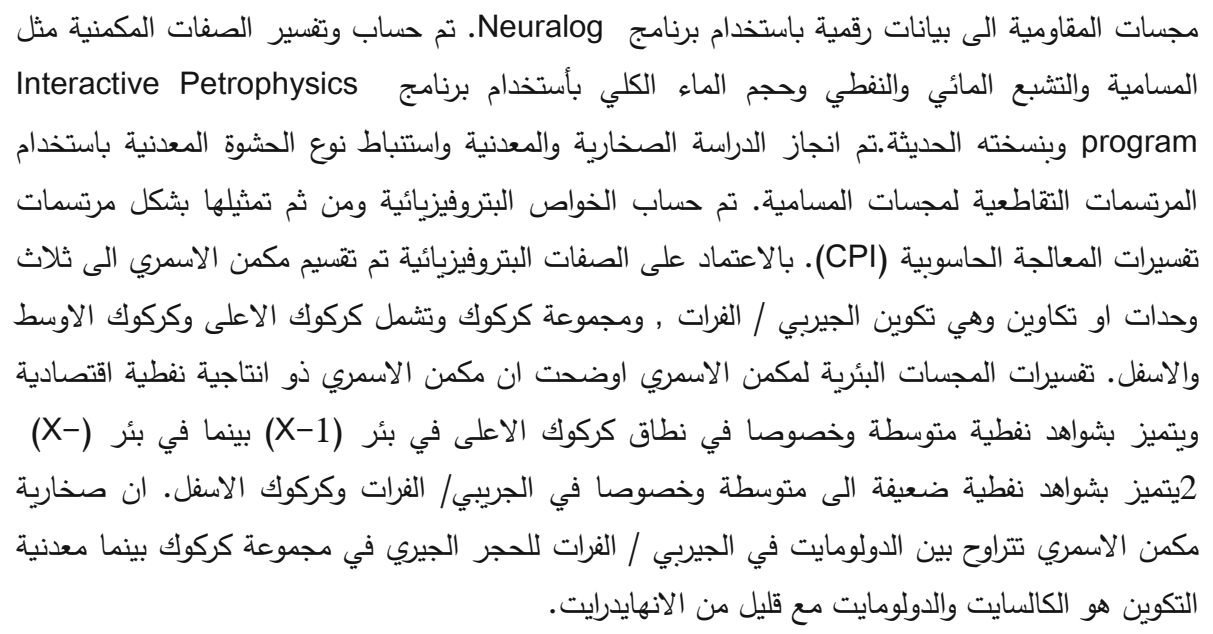

\section{Introduction}

The petrophysical evaluation represents the study of reservoir properties related to fluids, gases, hydrocarbons, and aqueous solutions. Well logging is a method used to make petrophysical measurements in subsurface earth formations through drilled boreholes in order to calculate both the physical and chemical properties of rocks and the fluid they contain [1]. The goal is to locate, define, and produce hydrocarbons from a reservoir and it is also known as an evaluation of the reservoir. This technology plays a pivotal role in hydrocarbon exploration and manufacturing industries due to the enormous amount of data that well logging can provide. These techniques can be used in all exploration and production phases of hydrocarbons. Hydrocarbon industry established rapid and highlevel production through the utilization well logging technology [2].

The purpose of this study is to make use of all the available data of well logs which are acquired from AG-32 and AG-36 wells of Abu Ghirab oil field to determine the petrophysical and lithological properties for each zone in Asmari reservoir. This study deals with pre-interpretation and the internal properties of Asmari reservoir.

\section{The Study Area}

Abu Ghirab oil field is located in in Missan governorate, south east Iraq, near the borders with Iran. It has an axial length of about $30 \mathrm{~km}$ and a width of about $5 \mathrm{~km}$, with coordinates of 3575000-360000 northing lines and 71000-73500 easting lines. It is composed of two domes, northern and southern, with a saddle zone [3], as shown in Figure-1. Abu Ghirab oil field tectonically belongs to the unstable shelf/ low folded zone/ Makhul-Hemrin subzone (Kirkuk embayment).This zone is very active in actions due to the collision between the Arabian and Iranian plates, where these actions led Abu Ghirab field to have a complex nature. According to seismic survey data, Abu Ghirab field is constructed from two non-symmetric culminations separated by a saddle (Figure-2). The axis of the structure is NW-SE. The length of the southern culmination is about $16.5 \mathrm{~km}$ with $5.5 \mathrm{~km}$ width, while the northern culmination is shared with Iran and it is possible that this part is a continuation of Dehleran field in Iran. The length of the northern culmination in Iraq is about $3 \mathrm{~km}$ with $2 \mathrm{~km}$ width. Many geological studies on Abu Ghirab structure referred that this structure was subjected to two types of forces caused by the folding movement; the first was tension forces concentrated on the upper part of the structure, while the second was compression forces on the lower parts of the structure that led to induce longitudinal tangential deformation with low intensity on the axis of the anticline and high deformation on the limbs [4]. 


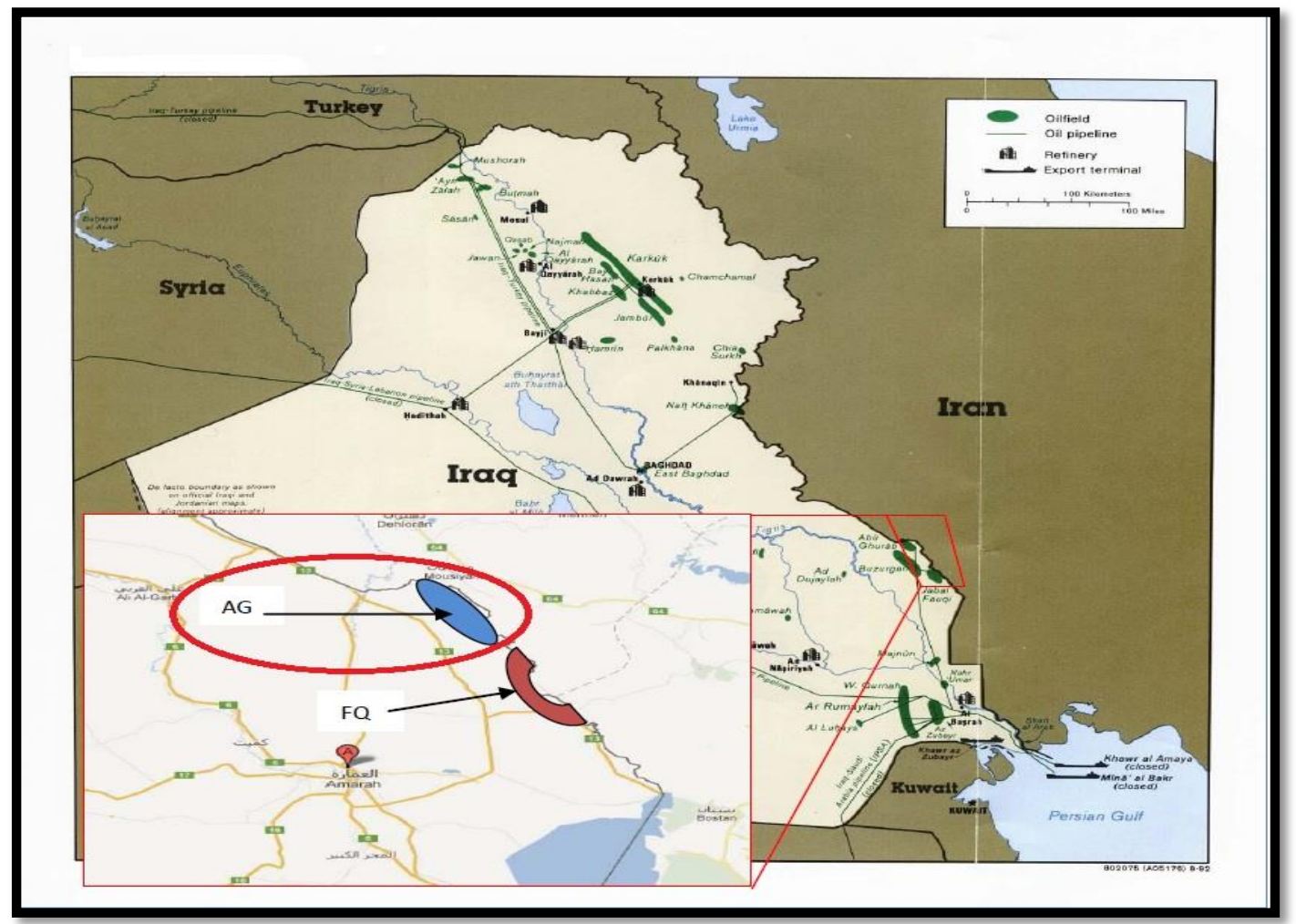

Figure 1-Location map of Abu Ghirab (AG) oil fields [5] .

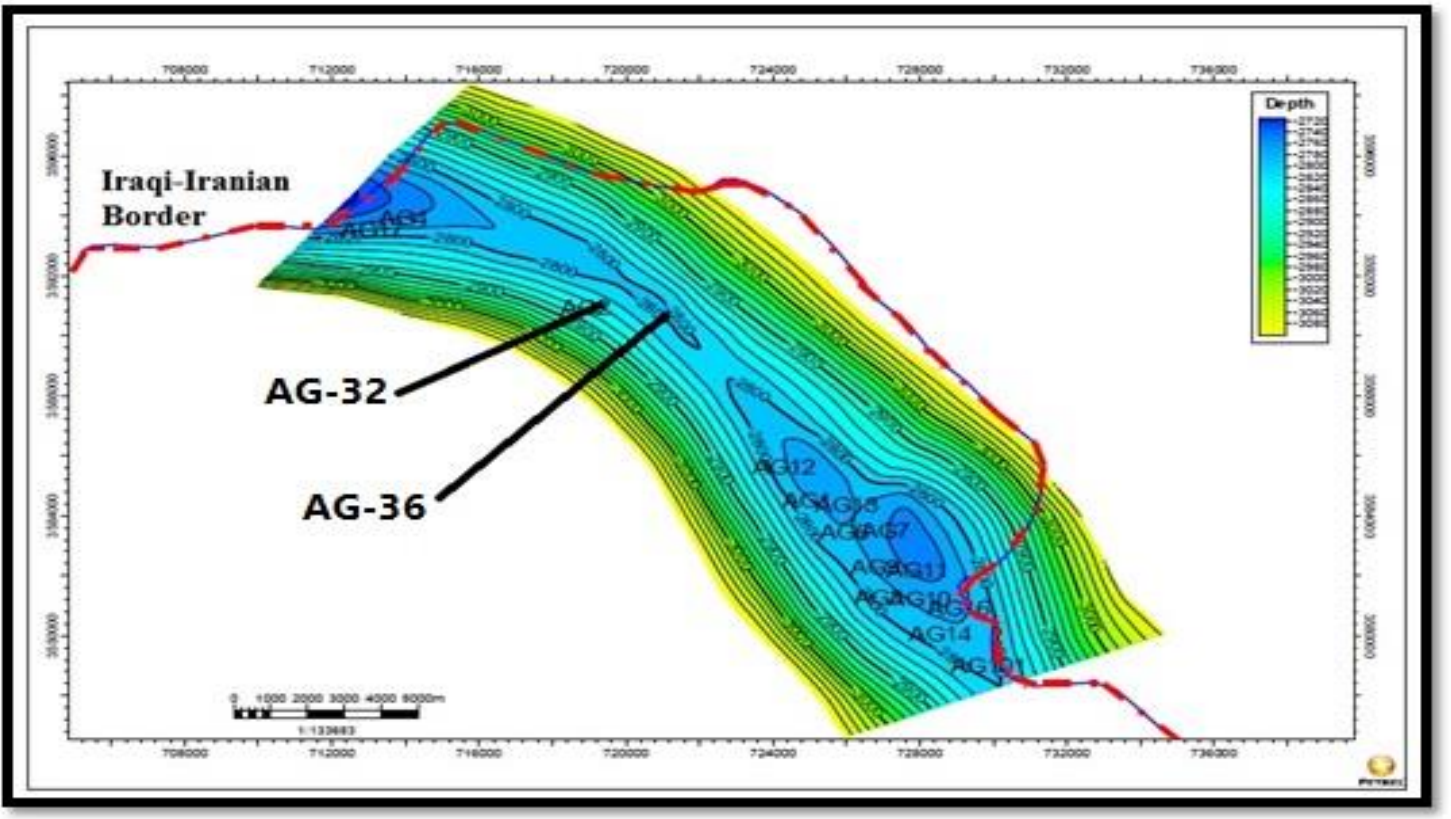

Figure 2-Structural map for top of Jeribe/ Euphrates Formations in Abu Ghirab oil fields [5].

\section{Depositional and Stratigraphic Settings}

Asmari Formation (Oligocene-Lower Miocene) is divided into four sub-forms; (1) Jeribe-Euphrate consists mainly of dolomite with some limestone and anhydrite. (2) Kirkuk Group is divided into three sub zones: A- upper Kirkuk consists mainly of limestone, dolomite and some sandstone. B- Buzurgan Member consists of dolomite, sandstone, limestone and upper shale in the upper part, but this member is not present in the wells under study. C- Middle-Lower Kirkuk is in general composed of limestone, dolomite, and sandstone with shale [5]. According to the type section, Kirkuk group is divided into upper, middle, and lower Kirkuk, with nine formations which were deposited during the Oligocene. These nine formations, depending on the environment, can be grouped into three types Figures- 
(3 and 4),; 1- Basinal (deep-sea) formations, including Palani, Tarjil and Ibrahim; 2- Lagoonal formations, including Shekh Alas, Baba, and Azkand are; 3- Reefal Formations, including Shurau, Bajawan and Anah Formations [6]. These formations are deposited in the Kirkuk and Ramadi areas in a relatively small basin. This basin's shape is elongated with northwest-southeast trend, opening from the south to open marine (ocean). These formations of the reef and the front reef are good reservoirs for oil accumulation and have actually penetrated into the production of oil.

\section{Objectives of the Study}

The main objective of this study is integrating petrophysical log data to qualify and quantify petrophysical properties to assess Asmari reservoir's production potential in Abu Gharib oil field . In particular, the objectives include:

the objectives include:

Determination of reservoir depth and thicknesses in the wells, determination of reservoir properties such as shale volume, porosity $(\Phi)$, fluid saturation, Interpretation of porosity logs and porosity data to analyse lithology of the formations and Integration of all the available data to evaluate the production potential of the wells.

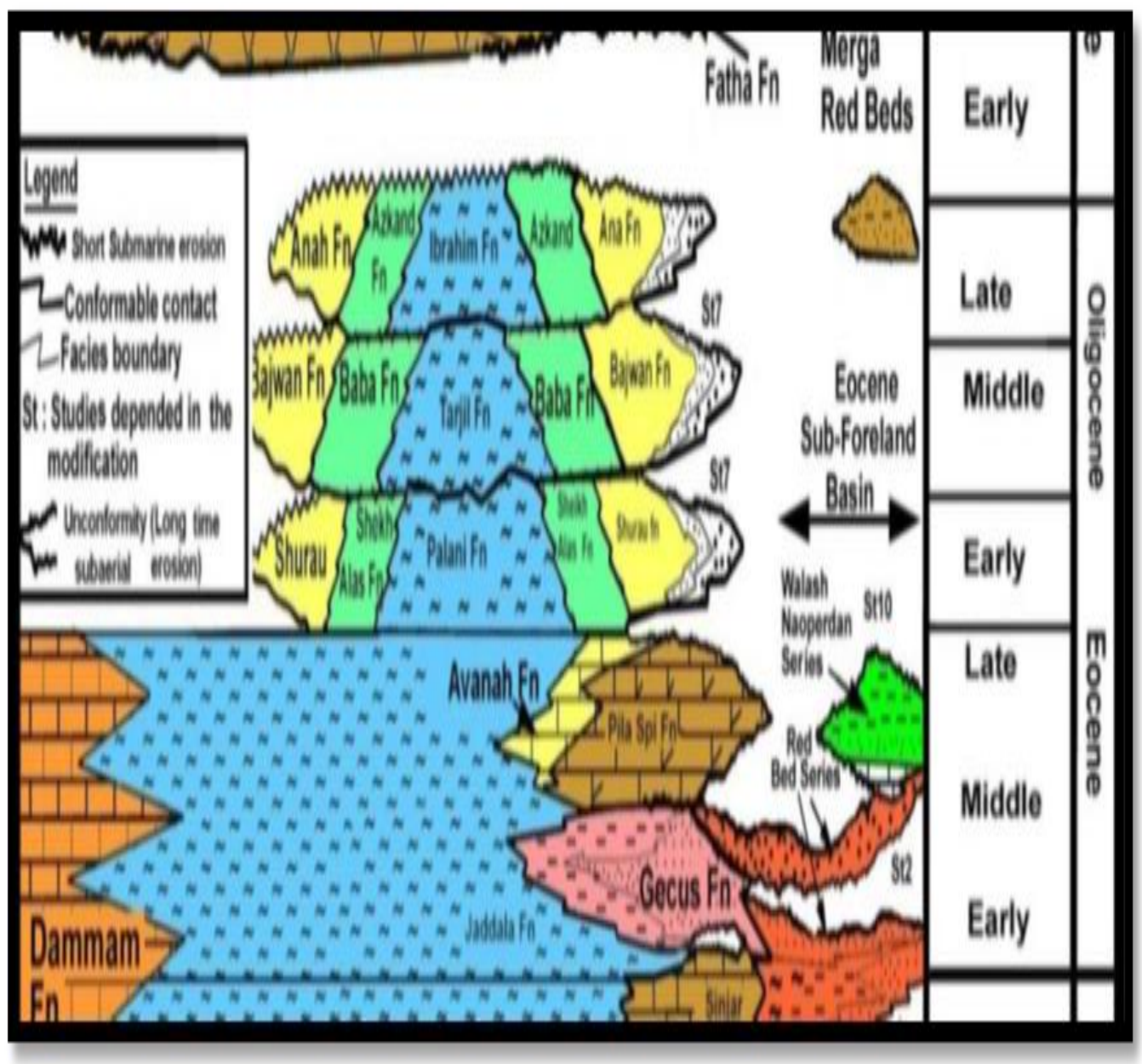

Figure 3-Chronostratigraphic column of the Oligocene showing the Formations of Kirkuk Group [7]. 


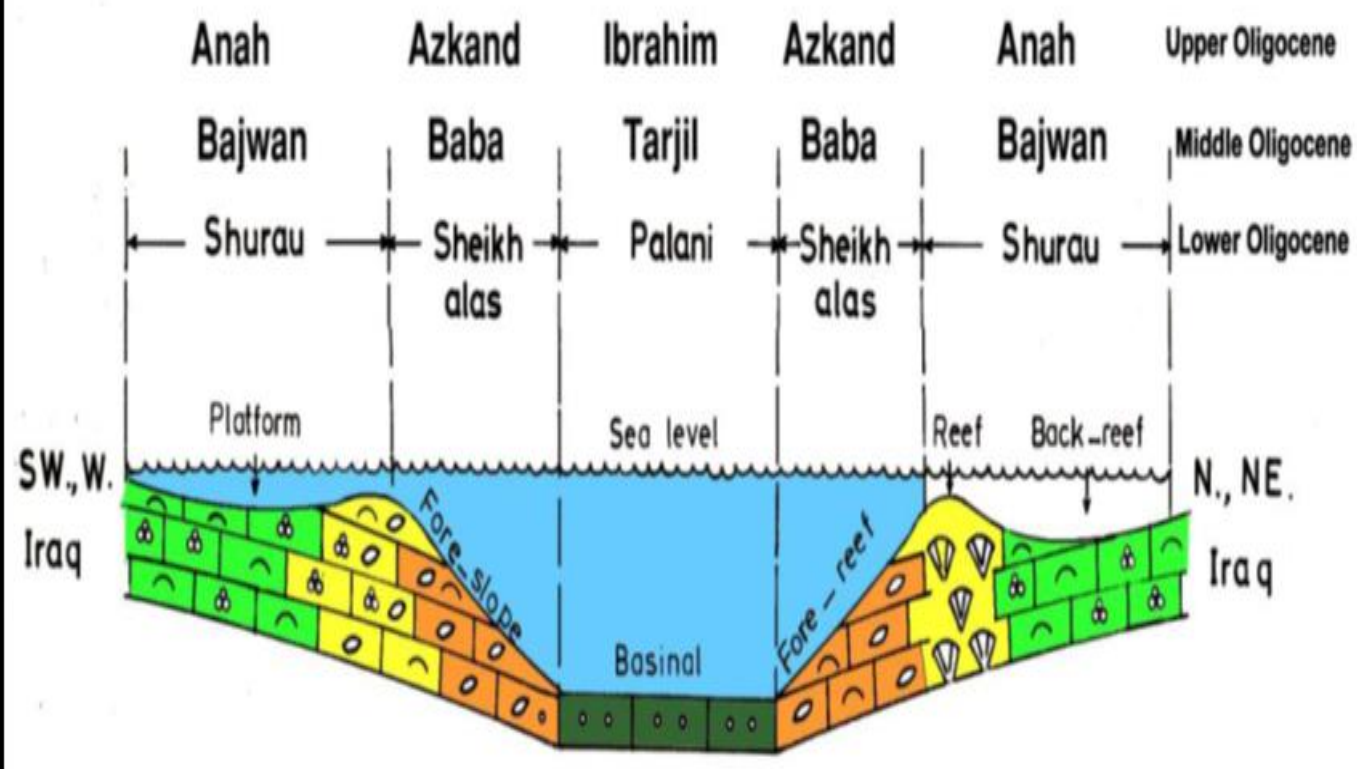

Figure 4-Geologic cross section of the Oligocene showing the Formations of Kirkuk [7].

\section{Materials and Methods}

The accessible open-hole logs (Caliper log, Spontaneous potential, Gamma ray, Density, Sonic, Neutron, and Resistivity Logs) of the investigated wells were used in this study. The available open $\log$ data was digitized for analysis and description to be imported into the IP software. Neuralog technology was used in this very first phase. One reading per $0.125 \mathrm{~m}$ depth was selected to measure the input data. The study consists of two steps: pre-interpretation and interpretation. The preinterpretation includes a determination of effective porosity and all the parameters necessary for the interpretation processes (corrected for shale effects). Definitions were made using the Interactive Petrophysics software v4.4, which is an interactive system for definitions of borehole environment and invasion effects and log corrections.

\section{Determination of Petrophysical Properties}

Petrophysical parameters were collected and evaluated using well logs for evaluating reservoir proper ties of the Asmari formation. These parameters include:

\section{1- Volume of shale (Vsh)}

To estimate Vsh from gamma ray (GR Log), it was essential to determine gamma ray index (IGR) by using the equation of Schlumberger (1974) [8]

$$
\text { IGR }=(\text { GRlog- GRmin }) /(\text { GRmax }- \text { GRmin })
$$

where GRlog = gamma ray reading of formation; GRmin = minimum gamma ray reading (clean sand or carbonate); GRmax = maximum gamma ray reading (shale). For the purpose of this work, the formula of Larionov (1969) [9] for Tertiary rocks was used to determine the shale volume

\section{2- Porosity}

$$
\text { Vsh }=0.083 *\left[2^{\left(3.7^{*} \text { IGR }\right)}-1\right]
$$

The combination of the neutron and density measurements is the most widely used for estimation of the average neutron - density porosity ( $\Phi$ N.D). This combination is named the total porosity $(\Phi t)$ which is the total amount of voids in the rock volume, calculated as follows:

$$
\emptyset \mathrm{t}=(\emptyset \mathbf{N}+\emptyset \mathrm{D}) / 2
$$


The term effective porosity $\Phi$ e means the amount of void space that is interconnected and thus able to transmit fluids in free shale formation. Фe was computed by the following equation (Schlumberger, 1998) [10].

\section{3- Water and Hydrocarbon Saturation}

$$
\emptyset \mathrm{e}=\emptyset \mathbf{t} *(1-V s h "
$$

To calculate water saturation of the uninvaded zone ( $\mathrm{Sw}$ ) and the invaded zone (Sxo), the following two equations, according to the Archie equation (1942), [11] were used :

$$
\begin{aligned}
& \mathbf{S w}=\{(\mathbf{a} * \mathbf{R w}) /(\mathbf{R t} * \mathbf{m})\}^{1 / \mathbf{n}} \\
& \mathbf{S x o}=\left\{(\mathbf{a} * \mathbf{R m f}) /\left(\mathbf{R x o} *{ }_{\mathbf{m}}\right)\right\}^{1 / \mathbf{n}}
\end{aligned}
$$

where $\mathrm{Rw}=$ resistivity of water formation that is determined using Pickett plot [12] suggested a method to estimate resistivity of formation's water using the cross plot of resistivity versus porosity in $100 \%$ water saturated zones, as shown in Figures- 5 and 6 ); $a=$ tortuosity factor $=$ empirical constant taking $(1)$ for carbonate rocks; $m=$ cementation factor $=(2)$ for carbonate rocks; $n=$ saturation exponent $=(2)$ for carbonate rocks.

Then, the hydrocarbon saturation was calculated using the following equation:

$$
\mathbf{S h}=\mathbf{1}-\mathbf{S w}
$$

Moveable hydrocarbon saturation was calculated based on Schlumberger equation (1998) [10]:

$$
\text { MOS }=\text { Sxo }- \text { Sw }
$$

Whereas residual oil saturation was calculated according to Schlumberger (1987) [13], as in the

$$
\text { following equation: } \mathbf{R O S}=\mathbf{1}-\mathbf{S x o}
$$

D- Bulk Volume Analysis: Bulk volume of water (BVW) is the product of the formation's water saturation $(\mathrm{Sw})$ and its porosity [14], calculated as:

$$
\mathbf{B V w}=\mathbf{S w} * \emptyset
$$

Also, the bulk volume of water in the invaded zone is calculated as follow:

\section{4- Estimation of Asmari Lithology Using Cross Plots}

$$
\mathrm{BVxo}=\mathbf{S x o} * \emptyset
$$

The neutron-density cross-plot is one of the oldest quantitative analysis methods, considered to be significant and very often used to provide appropriate porosity resolution and strong lithological resolution of quartz, calcite and dolomite. On the cross plot, there are three lithology lines, which are the sandstone (silica), limestone (calcite) and dolostone (dolomite). The lithology lines are usually marked in percent with porosity values. M-N cross plot is used to classify mineral mixtures of sonic, density, and neutron logs to provide lithology-dependent amounts, $\mathrm{M}$ and $\mathrm{N}$.

The porosity combinations cross plots (density vs. neutron cross plot, M-N, and matrix identification (MID) cross plot) were used to identify main lithology, mineralogy, and matrix of Asmari Formation, according to Schlumberger[15].

$$
\begin{gathered}
\mathbf{M}=(\Delta \mathrm{tfl}-\Delta \text { tlog }) /(\boldsymbol{\rho b}-\boldsymbol{\rho f}) \times \mathbf{0 . 0 1} \\
\mathbf{N}=(\emptyset \mathbf{O f}-\emptyset \mathbf{O}) /(\boldsymbol{\rho b}-\boldsymbol{\rho f})
\end{gathered}
$$

where $\Delta \mathrm{tf}=$ interval transit time in fluid $=189 \mathrm{~m} / \mathrm{s}$ for fresh water and $185 \mathrm{~m} / \mathrm{s}$ for salt mud.

$\Delta \mathrm{t}=$ interval transit time (the log reading).

$P b=$ formation bulk density (the log reading).

$P f=$ fluid density, $1 \mathrm{~g} / \mathrm{cm}^{3}$ for fresh water or $1.1 \mathrm{~g} / \mathrm{cm}^{3}$ for salt mud.

$\emptyset \mathrm{Nf}=$ neutron porosity for fluid $=1$.

$\varnothing \mathrm{N}=$ neutron porosity.

For the application of MID cross plot, the following equation was used[16]:

Rhomaa $=(\rho b-\emptyset$ ta $\rho f) /(1-\emptyset$ ta $) ..(14) \Delta$ tmaa $=(\Delta$ t log $-\emptyset$ ta $\Delta$ tf $) /(1-\emptyset$ ta $)$ 


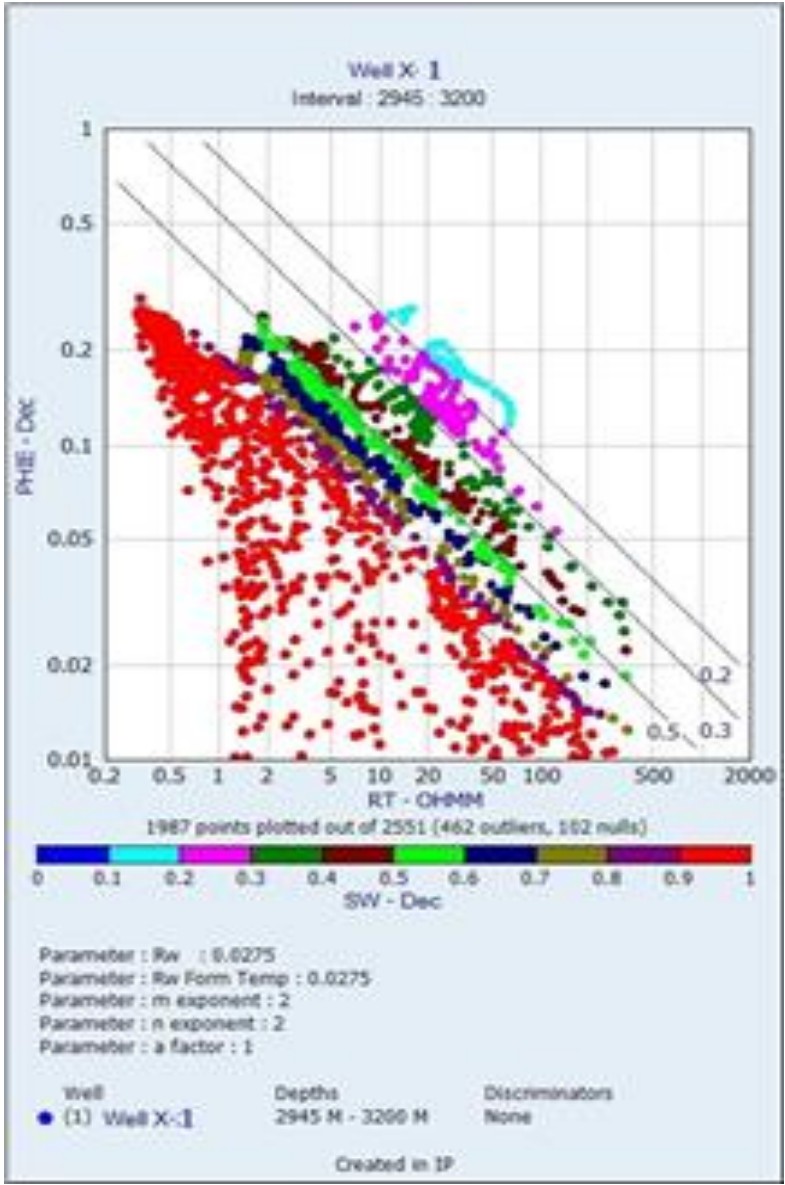

Figure 5- Pickett plot for well AG-32.

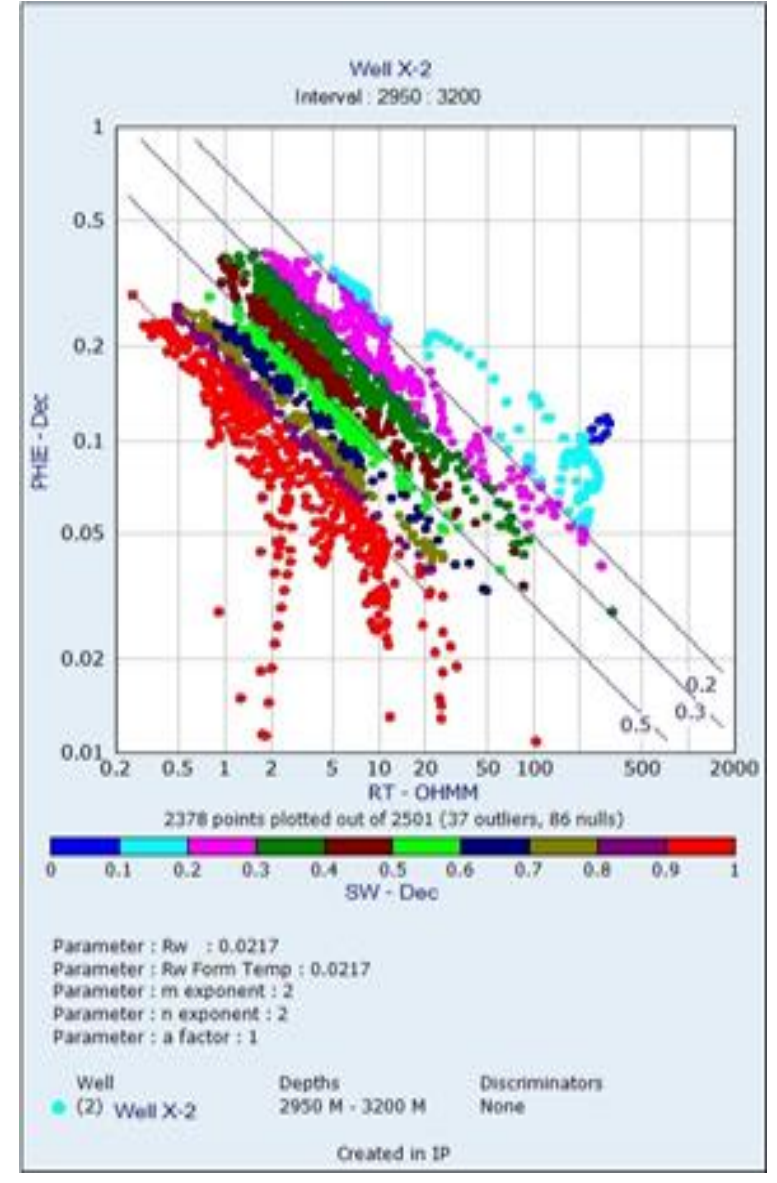

Figure 6-Pickett plot for well AG-36.

\section{Results and Discussion}

Figures-(7 and 8) illustrate the lithology of Asmari reservoir using neutron vs. density cross plots for the wells AG-32 and AG-36, respectively. These figures show that most of the points of JeribeEuphrates zone at both wells appear on the dolomite line, but the points of upper Kirkuk zone are mostly present on the limestone line. Also, the lithology of middle - lower Kirkuk zone consists mostly of limestone with a bed of sandstone, especially in the well AG-32, whereas well AG-36 does not contain sandstone bed. Figure- 8 of well AG-36 shows that middle - lower Kirkuk zone consists of limestone with few points on the sandstone line and a high ratio of clay.

Figures-9 and Figure-10 illustrate M-N cross plots for the mineralogy of wells AG-32 and AG-36, respectively. These figures show that the mineralogy of Asmari Formation consists mostly of calcite and dolomite with few amounts of quartz and anhydrite, especially in well AG-36. Figures-11 and Figure-12 illustrate the MID cross plot for matrix identification of wells AG-32 and AG-36, respectively. These figures show that the matrix of Asmari Formation consists mostly of calcite and dolomite. 


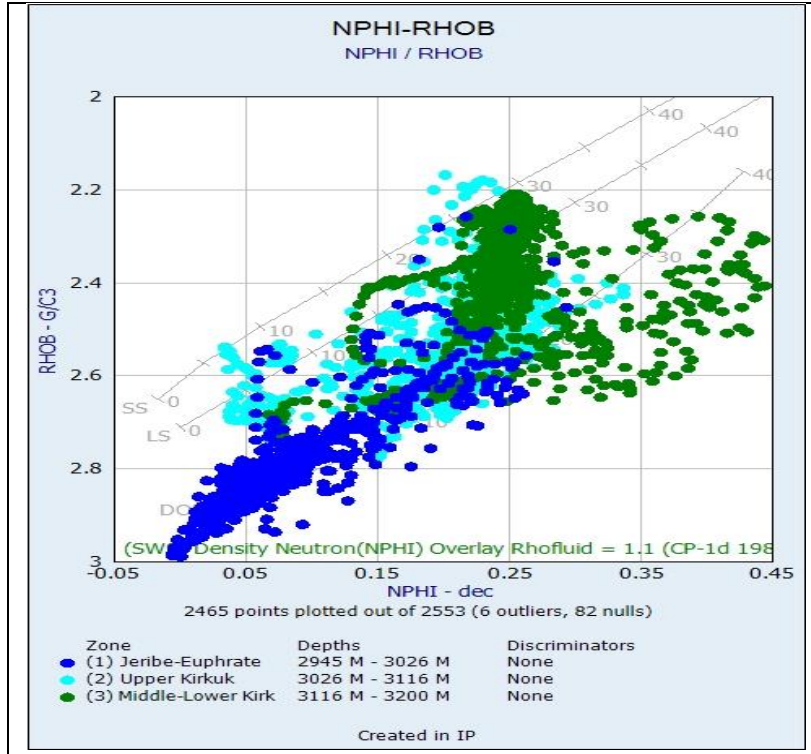

Figure 7-Lithology plot for well AG-32.

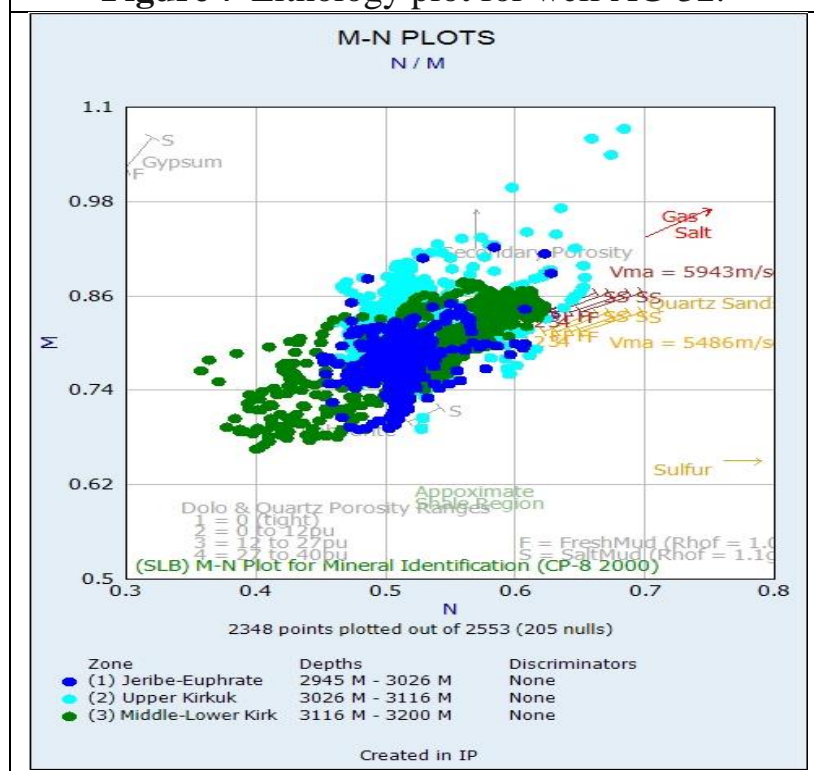

Figure 9-M-N cross plot for well AG-32.

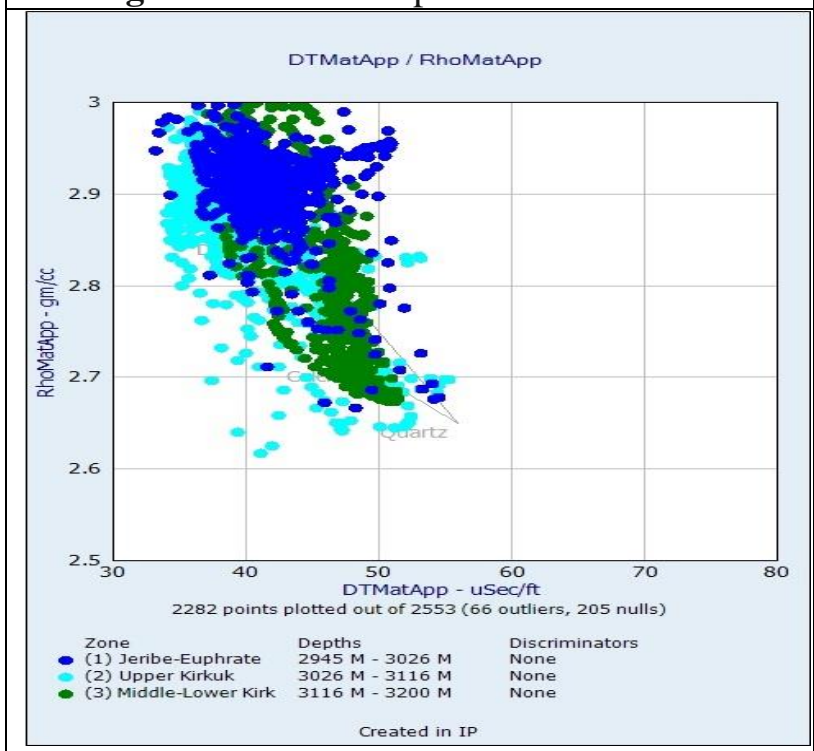

Figure 11-MID cross plot for well AG-32.

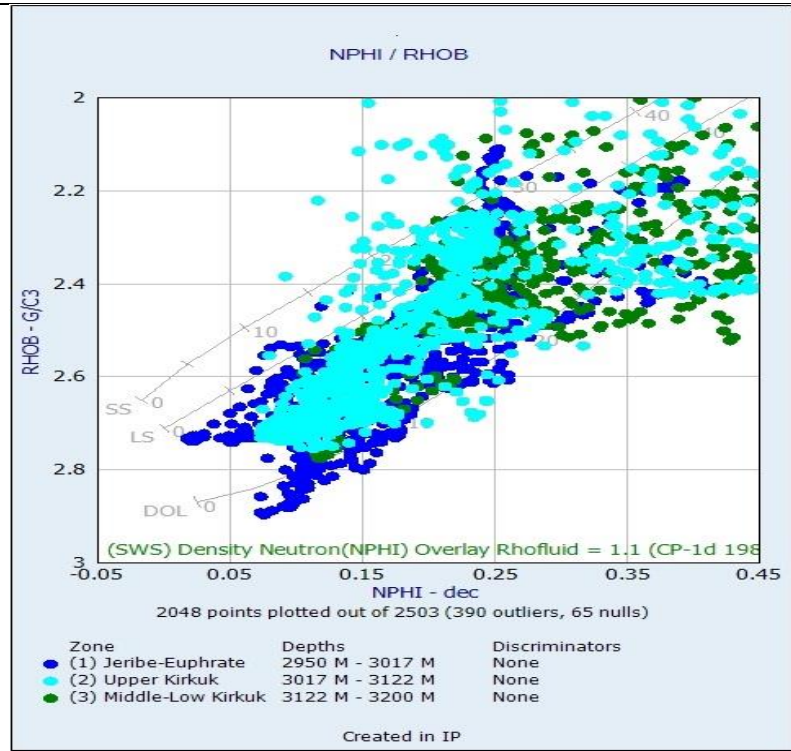

Figure 8-Lithology plot for well AG-36.

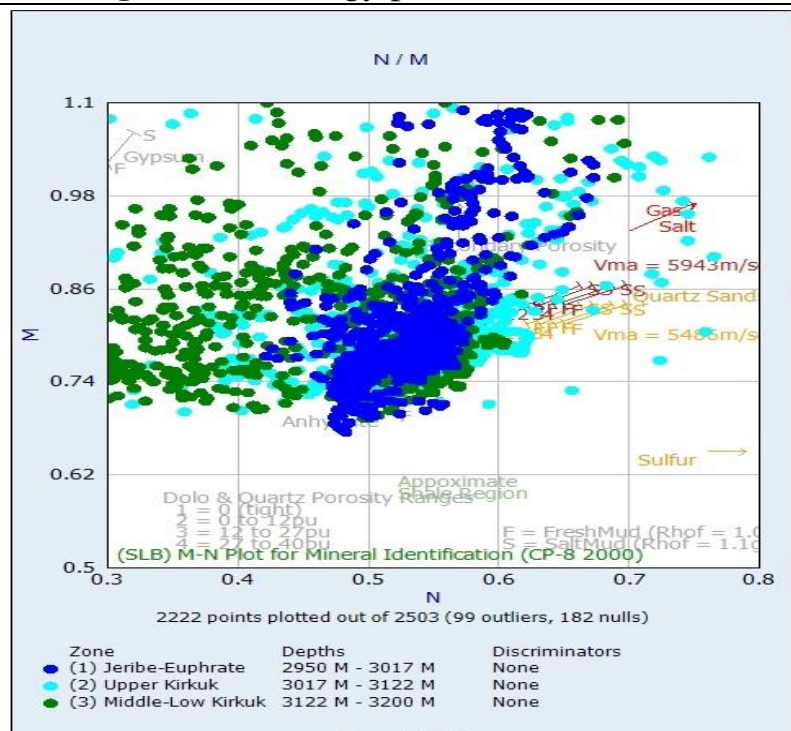

Created in IP

Figure 10-M-N cross plot for well AG-36.

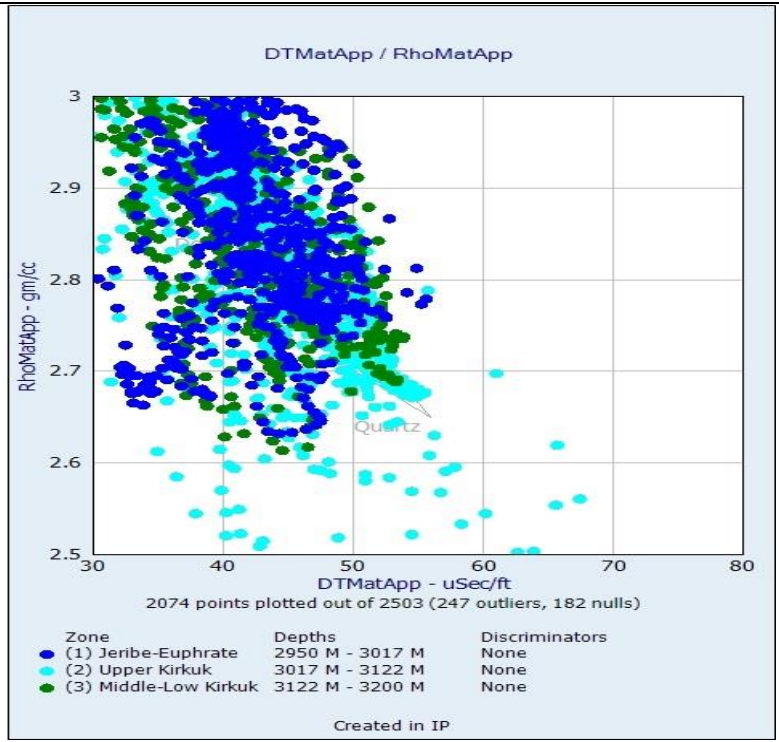

Figure 12-MID cross plot for well AG-36. 
Average petrophysical properties for Asmari Formation in the wells under study are presented in Tables-(1 and 2).

Figures- (13 and 14) show the CPIs of AG-32 and AG-36 wells, which were extracted from the code for Interactive Petrophysics (IP). The figures show the stages of the entire interpretation process, as follows:

The lithology track reflects the active porosity (PHIE), shale percentage (Vshale), and matrix percentages of dolomite, calcareous, and some sandstone beds. The components of effective porosity (PHIE), water-filled porosity in the invaded zone (BVWXO), and water-filled porosity in the non-invaded zone (BVW) include:

- The residual hydrocarbons are expressed in the area between PHIE and BVWXo.

-The zone of the moveable hydrocarbons is between BVWXo and BVW.

- Total hydrocarbons are in the area between PHIE and BVW.

Track of saturation, which represents a flushed and uninvaded area of water saturation. Track of porosity is the tracking of total porosity and secondary porosity In addition, the raw data of gamma ray, porosity, and resistivity logs are shown on tracks 1,2, and 3, respectively.

In general, CPI figures show that the Asmari reservoir is divided into three zones according to the interpretation of well logs: Jeribe- Euphrates zone with a thickness that ranges between $67 \mathrm{~m}$ in well AG-36 and $81 \mathrm{~m}$ in AG-32, upper Kirkuk zone which ranges in thickness between 90m in well AG-32 and $105 \mathrm{~m}$ in well AG-36, and the middle-lower Kirkuk zone with a thickness that ranges between $78 \mathrm{~m}$ in well AG-36 and 80m in AG-32. The Asmari Formation units are of variable quality regarding its petrophysical properties. The reservoir zones were qualitatively identified using all the available log signatures (gamma, resistivity, neutron, density, and sonic). In general, the Jeribe- Euphrates zone in well AG-32 is characterized by hard dolomitic facies with neglected porosity, as shown in the porosity track, very high density, and low neutron porosity, which indicates that the lithology of this zone is dolomite without any oil evidence because water saturation is very high . On the other hand, the Jeribe- Euphrates zone in well AG-36 is characterized by porous dolomitic limestone, indicating the presence of secondary porosity as well many oil evidence, especially in the lower parts of this zone.

The main reservoir in well AG-32 is the upper Kirkuk Formation that is characterized by porous limestone with good oil proposition to low water saturation and high hydrocarbon saturation. However, the same zone in the well AG-36 is characterized by high water saturation in most parts, which indicates the presence of weak oil shows. The middle-lower Kirkuk zone in well AG-32 is characterized by the existence of shale layer in the top of the zone, characterized by high gamma ray $\log$ values, as well as limestone and sandstone beds in the other parts. The middle-lower Kirkuk zone in well AG-32 consists mostly of shale with some beds of limestone, with decreased in gamma ray readings, but without sandstone bed. The middle - lower Kirkuk zone in well AG-32 represents a water bearing unit, but, on the contrary, this zone in well AG-36 represents porous shaly limestone with low water saturation, indicating the presences of high oil shows and an oil bearing zone.

Table 1-Average petrophysical properties for Asmari Formation in well AG-32.

\begin{tabular}{|c|c|c|c|c|c|c|c|}
\hline & SXO & SW & SPI & PHIE & PHIT & Vsh & BVW \\
\hline Asmari zones & $\mathbf{0 . 9 7 0}$ & $\mathbf{0 . 9 1 3}$ & $\mathbf{0 . 0 2 2}$ & $\mathbf{0 . 0 3 6}$ & $\mathbf{0 . 0 4 5}$ & $\mathbf{0 . 0 8 9}$ & $\mathbf{0 . 0 2 9}$ \\
\hline Jeribe/ Euphrates & $\mathbf{0 . 9 2 0}$ & $\mathbf{0 . 7 9 3}$ & $\mathbf{0 . 0 4 0}$ & $\mathbf{0 . 1 2 3}$ & $\mathbf{0 . 1 3 7}$ & $\mathbf{0 . 1 2 7}$ & $\mathbf{0 . 0 9 2}$ \\
\hline Upper Kirkuk & $\mathbf{1}$ & $\mathbf{1}$ & $\mathbf{0 . 0 1 0}$ & $\mathbf{0 . 1 8 3}$ & $\mathbf{0 . 1 6 7}$ & $\mathbf{0 . 2 7 7}$ & $\mathbf{0 . 1 3 8}$ \\
\hline
\end{tabular}

Table 2-Average petrophysical properties for Asmari Formation in well AG-36.

\begin{tabular}{|c|c|c|c|c|c|c|c|}
\hline Asmari zones & SXO & SW & SPI & PHIE & PHIT & Vsh & BVW \\
\hline Jeribe/ Euphrates & $\mathbf{0 . 7 4 9}$ & $\mathbf{0 . 5 8 7}$ & $\mathbf{0 . 0 0 6}$ & $\mathbf{0 . 1 2 9}$ & $\mathbf{0 . 1 4 2}$ & $\mathbf{0 . 0 9 2}$ & $\mathbf{0 . 0 6 5}$ \\
\hline Upper Kirkuk & $\mathbf{0 . 9 2 5}$ & $\mathbf{0 . 8 7 3}$ & $\mathbf{0 . 0 0 7}$ & $\mathbf{0 . 1 5 4}$ & $\mathbf{0 . 1 8 2}$ & $\mathbf{0 . 1 8 2}$ & $\mathbf{0 . 1 2 6}$ \\
\hline Middle-Lower Kirkuk & $\mathbf{0 . 9 5 6}$ & $\mathbf{0 . 8 2 2}$ & $\mathbf{0 . 0 1 9}$ & $\mathbf{0 . 2 1 1}$ & $\mathbf{0 . 2 5 6}$ & $\mathbf{0 . 3 0 1}$ & $\mathbf{0 . 1 6 2}$ \\
\hline
\end{tabular}




\section{Conclusions}

In general, CPI figures show that the Jeribe- Euphrates zone has porosity values that range from very poor to poor in well AG-32, according to the occurrence of massive dolomite as indicated by very high readings of density log. Whereas porosity of this zone in well AG-36 ranges from poor to fair. The upper Kirkuk zone and middle - lower Kirkuk zone in both wells are characterized by high porosity readings.

Analyses of well logs show that Asmari Formation is characterized by weak oil shows in well AG32 , especially in middle - lower Kirkuk zone. Nevertheless, the other parts of the formation, in the same well, are characterized by low readings of water saturation with some oil shows, as shown in upper Kirkuk zone. Asmari Formation in well AG-36 is characterized by more oil shows than those found in well AG-32, especially in the lower parts of Jeribe- Euphrates and in middle - lower Kirkuk zone, in addition to weak oil shows in middle - lower Kirkuk zone.

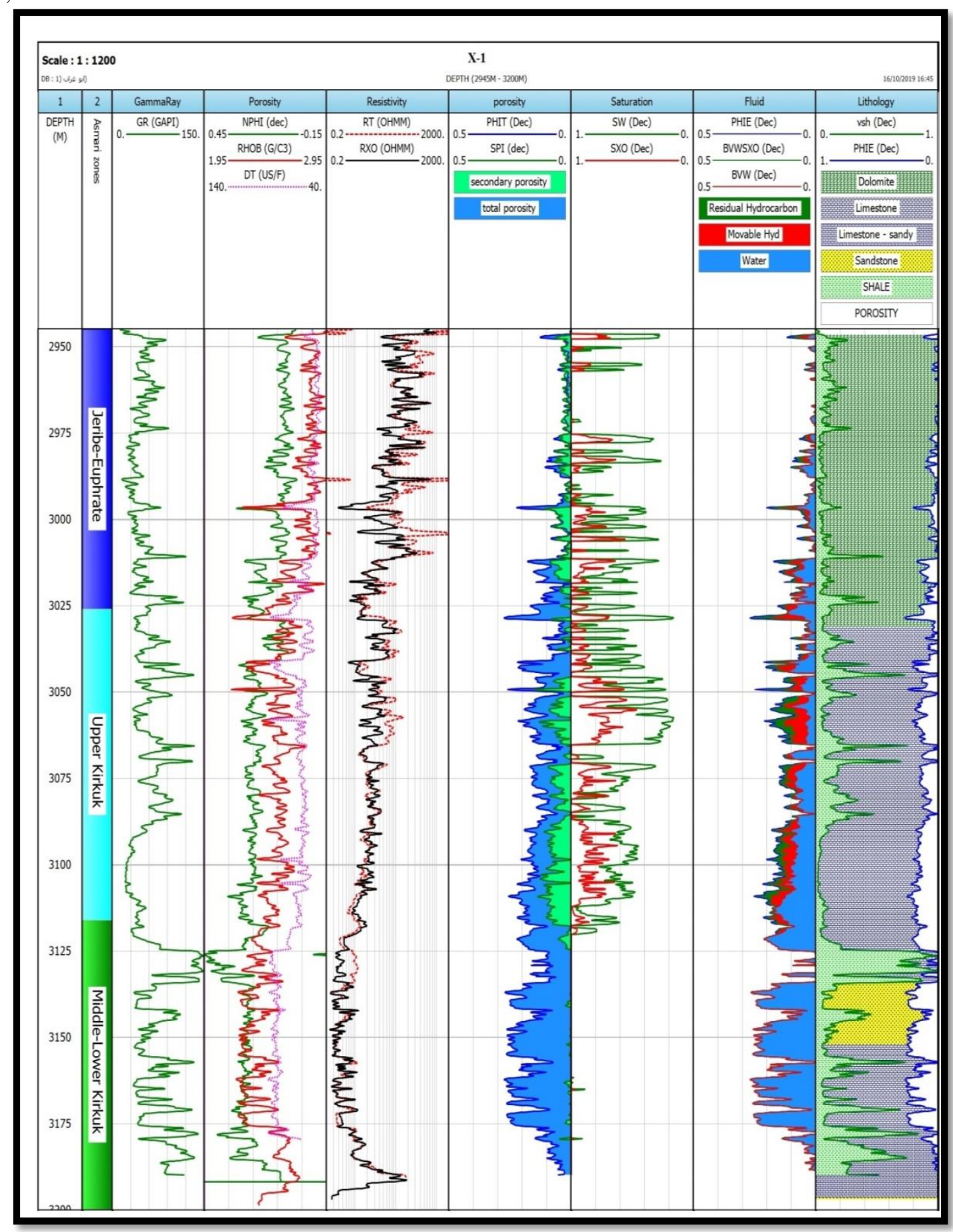

Figure 13-Computer processed interpretation (CPI) for well AG-32. 


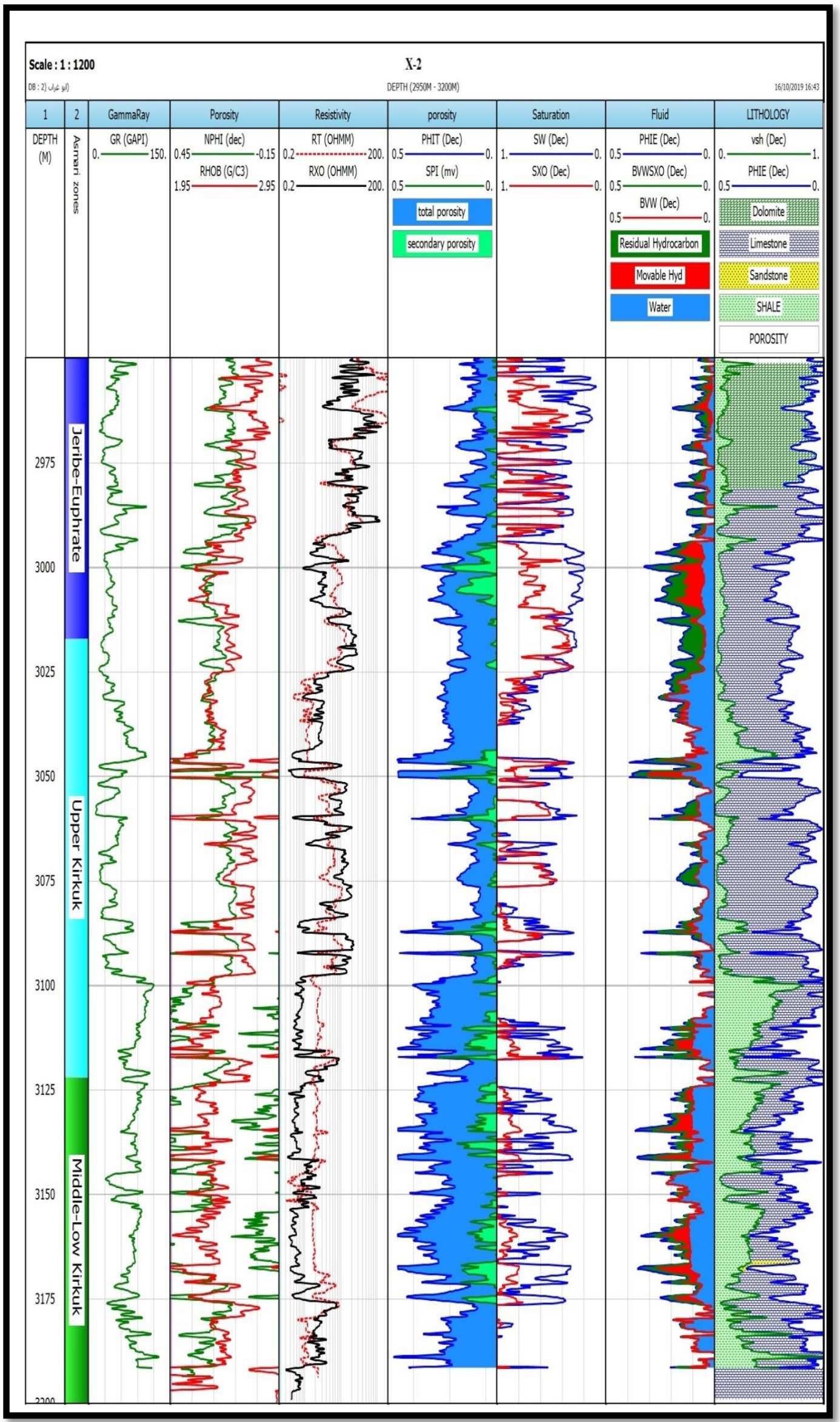

Figure 14-Computer processed interpretation (CPI) for well AG-36. 


\section{References}

1. Catuneanu, O. 2006. Principles of sequence Stratigraphy. Department of Earth and Atmospheric Scinces, University of Alberta, Canada. First Edition Elsevier Science Publishers Company INC. $375 \mathrm{pp}$.

2. Gonfalini, M. 2005. The Fundamental Role of Formation evaleuation in the E\&P Process. STYPED "Sponsor Team for young petroleum Engineers Development", March 24th, 2005, 28pp.

3. Alhuraishawy, Ali khayoon. 2005. "detection of natural fractures in asmari reservoir / Abughirab field by techniques of well logging and well testing", M.Sc. thesis petroleum engineering, university of Baghdad.

4. Alssad, H.F.K. 2010. Study and evaluate the Petrophysical and Geological Properties of the Southern Asmari Reservoir / Southeast Iraq. Unpublished Msc. Thesis, Basra University.

5. Alsinbili, M.B., Aljawad, S.N. and Aldalawy, A.A. 2013. Permeability Prediction of Un-Cored Intervals Using FZI Method and Matrix Density Grouping Method: A Case Study of Abughirab Field/Asmari FM., Iraq. Iraqi Journal of Chemical and Petroleum Engineering, 14(4): 27-34.

6. Jassim S. Z. and Goff J. C. 2006. Geology of Iraq . Dolin, Prague and Moravian Museum, Brno. $341 \mathrm{p}$.

7. AL-Hashimi, H.A. and Amer, R.M. 1986. Restudy of the Ibrahim Formation in the type section,Ibrahim Well No.1,Mosul area N.Iraq. Jour.,Geol., Soc., Iraq. 9(2): 93-100.

8. Schlumberger. 1974. Log Interpretation, vol. II-Applications, New York.

9. Larionov v.v. 1969. Borehole Radiometry, Moscow,U.S.S.R.,Nedra.

10. Schlumberger. 1998. Cased Hole Log Interpretation Principles/Applications, Houston, Schlumberger Wireline and Testing, 198p.

11. Archie, G.E. 1942. The Electrical Resistivity Log as an Aid in determining some Reservoir Characteristics; AIME, 146: 54.

12. Pickett, G.R. 1966. Review of Current Techniques for Determination of Water Saturation from Logs. Journal of Petroleum Technology (JPT), pp: 1425-1433.

13. Schlumberger 1987. Log interpretation charts, USA.

14. Asquith, G. B. and Krygowski, D. 2004 Basic Well Log Analysis, 2nd Edition: AAPG Methods in Exploration Series 16. Published by The American Association of Petroleum Geologists Tulsa, Oklahoma, 244p.

15. Schlumberger. 2005. Log Interpretation Charts. Houston.

16. Schlumberger. 1972. Log Interpre[tation, Vol. I- principles: New York, Schlumberger Ltd.,112 p. 